\title{
Evaluation of microwave-dried black soldier fly (Hermetia illucens) larvae meal as a dietary protein source in broiler chicken diets
}

\author{
B. Kim, H.R. Kim, Y.-C. Baek, C.H. Ryu, S.Y. Ji, J.Y. Jeong, M. Kim, H. Jung and S.H. Park" \\ Animal Nutrition E Physiology Team, National Institute of Animal Science, Rural Development Administration, Wanju \\ 55365, Republic of Korea; shwa6560@korea.kr
}

Received: 29 June 2021 / Accepted: 3 August 2021

(c) 2021 Wageningen Academic Publishers

OPEN ACCESS CC (i) RESEARCH ARTICLE

\begin{abstract}
Here, the effect of microwave-dried black soldier fly (Hermetia illucens) larvae meal (HILM) as a dietary protein source on the growth performance and health of broilers was evaluated. A total of 126 male broilers were randomly allocated to three treatments (six replicates of seven birds per group): control diet (CON) of corn and soybean meal and two experimental diets in which soybean meal was replaced with $25 \%$ (25HILM) or 50\% (50HILM) HILM. The broilers were slaughtered at $35 \mathrm{~d}$ to determine the apparent ileal digestibility (AID), volatile fatty acid (VFA) profiles, and length and weight of the small intestine. Blood samples were collected from 36 randomly selected birds (12 broilers per treatment) to determine serum parameters and haematological traits. Average daily gain, feed intake, and AID of protein were decreased $(P<0.05)$ in the 50HILM group compared with those in the CON group. Dietary HILM increased $(P<0.05)$ the relative length of the entire digestive tract and total VFAs in the caecal digesta. Serum low-density lipoprotein cholesterol was the lowest $(P<0.01)$, but the triglyceride levels were the highest $(P<0.05)$ in the 50HILM group. The serum phosphorus level was lower in both HILM diet-fed groups $(P<0.01)$, whereas the creatine phosphokinase level was lower in the 50HILM group than in the CON group. In contrast, the 50HILM group showed higher $(P<0.05)$ monocyte and red blood cell distribution width-standard deviation. In conclusion, dietary microwave-dried HILM positively influenced the VFA and cholesterol levels; however, growth performance was negatively affected by malnutrition caused by low protein digestibility in the 50HILM group. Microwave-dried HILM is a valuable ingredient for broiler diets, with up to $25 \%$ substitution showing no detrimental effects on growth performance and health. Further studies are needed to improve HILM digestibility.
\end{abstract}

Keywords: digestibility, protein source, soybean meal, volatile fatty acid

\section{Introduction}

Soybean meal (SBM) is the main protein source in animal feed, and increasing demand for protein sources (e.g. soybean) has led to competition for resources (Schiavone et al., 2017). Therefore, a sustainable alternative feed source with high protein content and amino acid profiles comparable to that of SBM is required. Insects contain high-quality proteins and are considered as an alternative protein source for poultry (Bovera et al., 2015). Particularly, black soldier fly (Hermetia illucens, HI) larvae may be useful as a feed ingredient and can be used as a countermeasure to control increasing organic waste in the future (Surendra et al., 2016). In contrast to their transforming ability from food waste biomass to valuable feed ingredients, there is a concern in terms of safety such as bioaccumulation of heavy metals in their body from contaminated rearing substrates (Diener et al., 2015; Gasco et al., 2020). Studies have shown that hazardous heavy metal concentrations in animal products such as chicken meats and eggs have no negative effects (Park et al., 2021; Schiavone et al., 2019).

HI larvae contain high levels of protein ( 35 to $57 \%$ ) and fat (35\%) and HI larvae meal (HILM) has a relatively higher crude protein (CP) content (61.24 vs $45.76 \%$ ) than SBM (Park et al., 2021; Veldkamp et al., 2012). However, they also have a considerably high chitin content in their exoskeletons (Marono et al., 2017; Nafisah et al., 2019; 
Park et al., 2021). Chitin is indigestible and can bind to proteins and decrease their digestibility (Borrelli et al., 2017; Longvah et al., 2011). Although birds naturally consume insects and can hydrolyse chitin in their gut (Tabata et al., 2017), HILM can also negatively affect nutrient digestibility, as poor growth performance was observed when HILM was included in bird feed (Cutrignelli et al., 2018; Dabbou et al., 2018; De Marco et al., 2015; Suzuki et al., 2002). However, chitin may also act as a potential indigestible prebiotic to increase the production of volatile fatty acids (VFAs) and modulate the gut microbiota (Borrelli et al., 2017; Cutrignelli et al., 2018; Kawasaki et al., 2019). Furthermore, chitin has been shown to stimulate an immune response without negatively affecting growth performance (Bovera et al., 2015) and has positive effects on the health of laying hens; a higher globulin value and lower albumin-to-globulin ratio (A/G), which are indicators of better disease resistance, were observed in hens fed a chitin-rich diet (Bovera et al., 2018; Marono et al., 2017).

HILM also contains a higher lipid content than SBM, and fatty acid (FA) profiles are characterised by high and low levels of saturated FAs and unsaturated FAs (UFAs), respectively, in HILM (Bovera et al., 2018; Schiavone et al., 2019). Additionally, it has been reported that the FA profiles of chicken breast meat from HILM-fed broilers showed increased UFA and polyunsaturated FA ratios (Schiavone et al., 2019). HILM has been suggested as a valuable protein source for broilers; however, the FA profile of HILM should also be considered in the context of providing healthy chickens for modern consumers (Schiavone et al., 2019). Therefore, further studies are required to determine the effects of HILM on the growth performance and overall health of broilers in terms of both chitin and FA profiles.

A recent study showed that the drying method affected the structures of proteins in HILM (Huang et al., 2019; Schiavone et al., 2017). It has also been suggested that structural changes in proteins caused by microwave drying can decrease the digestibility of HILM (Huang et al., 2019). However, the microwave drying method has advantages to manage moisture content in the HI larvae and to produce products time efficiently compared to other drying methods (Khodifad et al., 2020; Lenaerts et al., 2018). Nevertheless, the effects of microwave-dried HILM on the growth and health of broilers are not well-understood. Thus, in this study, we examined the effects of microwave-dried HILM on the growth performance and health of broiler chickens. The effects of two different substitution levels (25 and $50 \%$ ) of SBM by HILM on growth performance, apparent ileal digestibility (AID), caecal VFA production, and blood traits were evaluated.

\section{Materials and methods}

\section{Insect meal}

After hatching ( $3-4$ days; $\left.27^{\circ} \mathrm{C}\right)$, the HI larvae were reared (10-15 days, $27 \pm 3^{\circ} \mathrm{C}$ ) on household food waste. Before manufacturing, the $\mathrm{HI}$ larvae were fasted for two days and cleaned to remove waste from their bodies. The cleaned HI larvae were dehydrated and dried using a microwavedrying oven $\left(70-80^{\circ} \mathrm{C} ; 30 \mathrm{~min}\right)$. The dried $\mathrm{HI}$ larvae were defatted at $45-48^{\circ} \mathrm{C}$ using a cold press oil machine (NF-80; Karaerler, Ankara, Turkey) to preserve nutritional quality from heat. The experimental diets were mixed using the pulverised $\mathrm{HI}$ larvae and other feed ingredients.

\section{Birds, diets, and experimental design}

This study was approved by the Institutional Animal Care and Use Committee of the Rural Development Administration (no. NIAS-2020-497) and conducted in the poultry facility of the National Institute of Animal Science of South Korea.

A total of 126 male broiler chicks (Ross 308; one-day-old) were randomly assigned to three dietary treatments (six replicates of seven birds per treatment). Three experimental diets were formulated to meet or exceed the nutrient requirements for three phases (NIAS, 2017): starter (days 1-7), grower (days 7-21), and finisher (days 21-35). The control group (CON) was fed a diet based on corn and SBM. In each phase, 25 and $50 \%$ of SBM were partially replaced with the HILM (25HILM and 50HILM groups, respectively) in the treated groups; the inclusion levels of the HILM were $7.5,7$, and $6.5 \%$ in the 25HILM group and 15,14 , and $13 \%$ in the $50 \mathrm{HILM}$ group. The feed ingredients and chemical composition of the experimental diets are reported in Table 1. Furthermore, the chemical composition and the FA profile of HILM and SBM were analysed as shown in our previous study (Kim et al., 2021). Feed and water were provided ad libitum throughout the trial. An indigestible marker (chromic oxide; $\mathrm{Cr}_{2} \mathrm{O}_{3}$ ) was added to all diets at a level of $2.5 \mathrm{~g} / \mathrm{kg}$ to estimate the AID of nutrients.

\section{Growth performances}

The initial body weight ( $\mathrm{d}$ 1), live body weight, and feed intake were recorded at the end of each growth phase (d 7,21 , and 35). These parameters were used to calculate the average daily gain and average daily feed intake. The feed conversion ration (FCR) was also determined for each growth phase and overall experimental period. Health status and mortality were monitored and recorded daily. 
Table 1. Compositions and nutrient levels of the experimental diets (as-fed basis). ${ }^{1}$

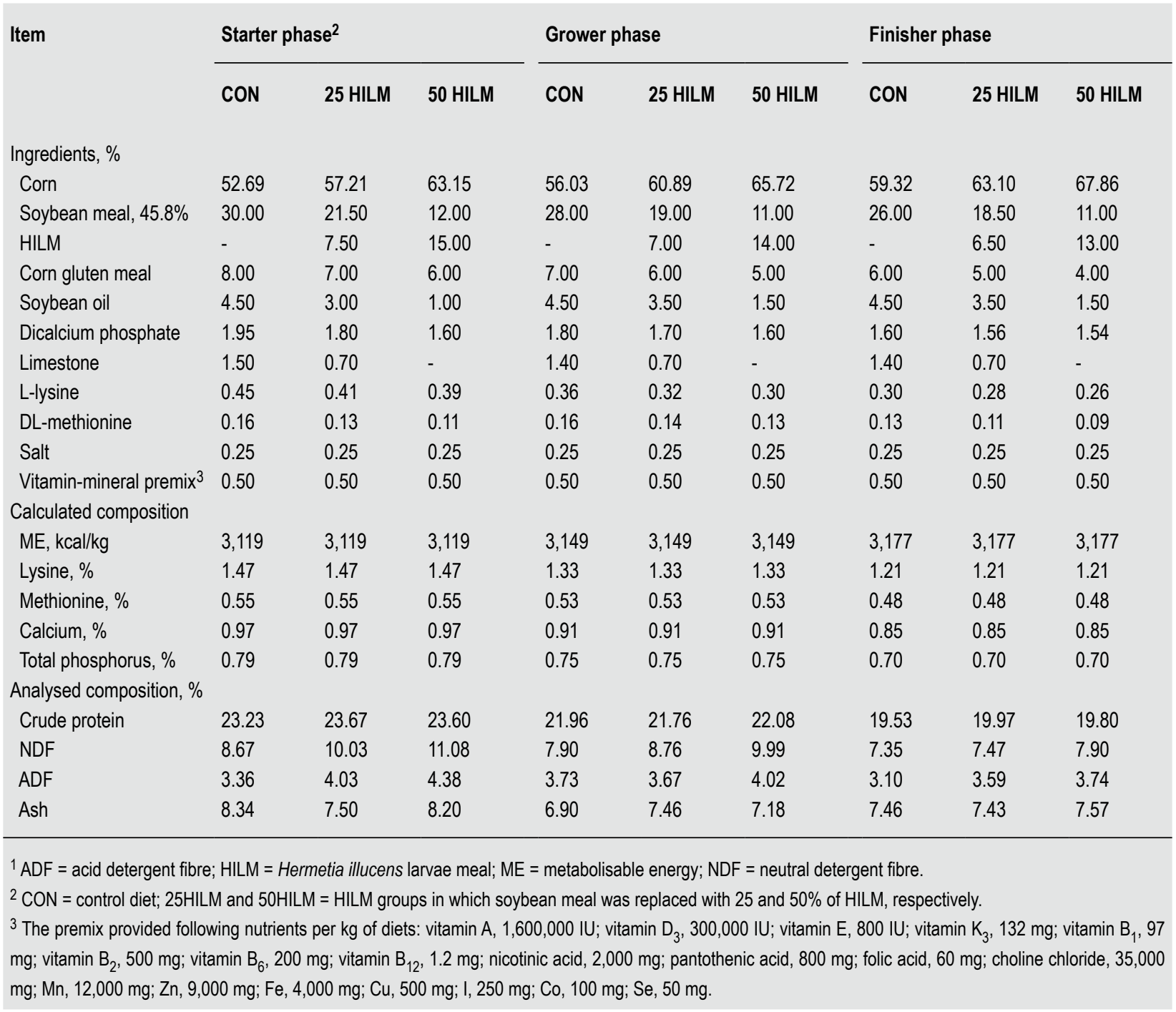

\section{Slaughtering procedures}

At 35 days of age, three birds were randomly chosen per pen (18 broilers per treatment) based on their final body weights and slaughtered by cutting the carotid artery. The digestive tract was excised, and each segment of the small intestine was identified. The segments were emptied, and their length and weight were recorded to calculate the relative length and weight. The ileal digesta samples from $20 \mathrm{~mm}$ after Meckel's diverticulum to $40 \mathrm{~mm}$ proximal to the ileocolic junction were gently squeezed and flushed into plastic containers for the digestibility analysis. A pair of ceca was also separated to collect caecal digesta for VFA analysis.

\section{Digestibility trial and calculation}

The collected ileal digesta samples from three birds were pooled (six pools per treatment), frozen immediately, and freeze-dried. The dried ileal digesta samples were ground through a 1-mm screen before chemical analysis.

Dry matter (DM), CP, and energy content were analysed in both the diet and ileal digesta samples based on previously described methods for the AID of the DM, CP, and energy (AOAC, 2005). The diets and ileal samples were analysed to determine the DM content. The energy content and CP were measured using bomb calorimetry (Parr 6300; Parr Instrument, Moline, IL, USA) and the Kjeldahl method (VAPO45; Gerhardt Ltd., Königswinter, Germany), respectively. The concentrations of $\mathrm{Cr}_{2} \mathrm{O}_{3}$ in the diets and ileal samples were determined by graphite furnace atomic absorption spectrometry. The AID of the DM, CP, and energy was calculated using the following equation (Stein 
et al., 2007): $100-100 \times[(\%$ nutrient in the ileal digesta/\% nutrient in the diet $) \times\left(\mathrm{Cr}_{2} \mathrm{O}_{3}\right.$ in the diet $/ \mathrm{Cr}_{2} \mathrm{O}_{3}$ in the ileal digesta)].

\section{Volatile fatty acids analysis}

At the time of slaughter (day 35), the caecal digesta samples were collected from one bird per pen (six broilers per treatment) and stored at $-80^{\circ} \mathrm{C}$ until analysis. Approximately $1 \mathrm{~g}$ of caecal digesta sample was diluted with $1 \mathrm{ml}$ of distilled water and centrifuged at $5,000 \times g$ at $4{ }^{\circ} \mathrm{C}$ for $10 \mathrm{~min}$. The supernatant was added to $200 \mu \mathrm{l}$ of metaphosphoric acid and centrifuged $(10 \mathrm{~min}$ at $5,000 \times g)$. The clear supernatant was used to measure VFA concentrations in the caecal digesta samples by gas chromatography (6890N Agilent Technologies) equipped with a capillary column $(15 \mathrm{~m}$ $\times 0.53 \mathrm{~mm} \times 0.5 \mu \mathrm{m}$; Supelco, Inc., Bellefonte, PA, USA).

\section{Blood analysis}

Before slaughter (day 35), blood samples were collected from the wing vein of two birds per pen (12 broilers per treatment) and placed in EDTA tubes and serumseparating tubes. The serum samples were separated by centrifugation at $1,800 \times g$ for $15 \mathrm{~min}$ and stored at $-20{ }^{\circ} \mathrm{C}$ until analysis. Glucose, total protein, albumin, globulin, cholesterol, high-density lipoprotein cholesterol, lowdensity lipoprotein cholesterol (LDL-C), triglycerides (TG), phosphorus, calcium, aspartate aminotransferase, alanine aminotransferase, gamma-glutamyl transferase, alkaline phosphatase, total bilirubin, blood urea nitrogen, creatinine, and creatine phosphokinase (CPK) were measured using an automatic biochemical analyser (Catalyst Dx, IDEXX Labs, Inc., Westbrook, ME, USA). The A/G was then calculated. EDTA-anticoagulated blood samples were analysed for blood cell count (white and red blood cells), haemoglobin, haematocrit, and red blood cell distribution width-coefficient of variation (RDW-CV) and -standard deviation (RDW-SD) using an automatic blood analyser (BC-5300Vet, Mindray, Hamburg, Germany).

\section{Statistical analysis}

All data were processed using the GLM procedure of SAS version 9.4 (SAS, Inc., Cary, NC, USA). For growth performance, the experimental unit was the pen; for AID, the experimental unit was a pooled ileal digesta sample from three birds; for VFA concentrations and blood parameters, the experimental unit was an individual bird. Statistical differences among treatments were determined using Tukey's multiple comparison test using the SAS software (SAS, 2009). Data are reported as mean \pm standard error of the mean. Significance and tendency were considered at $P<0.05$ and $0.05<P<0.10$, respectively.

\section{Results}

\section{Growth performance}

The growth performance of the broilers is summarised in Table 2 . The initial body weight did not differ $(P>0.05)$ following the different dietary treatments. The final body weight, average daily feed intake, and average daily gain decreased $(P<0.0001)$ in the 50HILM group compared with those in the CON and 25HILM groups. The FCR tended to increase $(P=0.0615)$ based on the inclusion level of HILM.

\section{Ileal digestibility}

As presented in Table 3, the AID of CP was lower $(P<0.05)$ in the 50HILM group than in the CON group. However, the AID of DM and energy was not affected $(P>0.05)$ by dietary HILM.

\section{Relative length and weight of small intestine}

The results of the relative length and weight of the small intestine are shown in Table 4 . The relative length of the entire digestive tract significantly $(P<0.01)$ increased in the 50HILM group compared with that in the CON and 25HIILM groups. The relative length of the ileum was significantly $(P<0.05)$ different in the 50HILM group compared with that in the CON and 25HILM groups. Moreover, the relative length of the duodenum $(P=0.0510)$ and jejunum $(P=0.0593)$ tended to increase with HILM inclusion. The relative weight of the entire digestive tract was not affected by HILM. However, the relative weight of the duodenum significantly $(P<0.05)$ increased in the 25HILM group compared with that in the CON group.

Table 2. Effect of dietary Hermetia illucens larvae meal (HILM) inclusion level on the growth performance of broiler chickens., ${ }^{1,2}$

\begin{tabular}{lllllll} 
Item & \multicolumn{2}{l}{ Dietary treatment $^{3}$} & \multicolumn{3}{c}{ SEM } & $P$-value \\
\cline { 2 - 4 } & CON & 25HILM & 50HILM & & \\
IBW (g, d 1) & 42.74 & 43.24 & 42.81 & 0.26 & 0.4011 \\
FBW (g, d 35) & $1,700.37^{a}$ & $1,619.50^{a}$ & $1,368.80^{b}$ & 36.01 & $<0.0001$ \\
ADFI (g) & $70.30^{\mathrm{a}}$ & $70.69^{\mathrm{a}}$ & $62.07^{\mathrm{b}}$ & 0.89 & $<0.0001$ \\
ADG (g) & $47.36^{\mathrm{a}}$ & $45.04^{\mathrm{a}}$ & $37.89^{\mathrm{b}}$ & 1.03 & $<0.0001$ \\
FCR (g/g) & 1.49 & 1.57 & 1.65 & 0.05 & 0.0615 \\
\hline
\end{tabular}

${ }^{1} \mathrm{ADFI}=$ average daily feed intake; $A D G$ = average daily gain; $F B W=$ final body weight; FCR = feed conversion ratio; IBW = initial body weight; SEM = standard error of the mean.

2 Values with different superscripts in the same row are significantly different $(P<0.01)$.

${ }^{3} \mathrm{CON}=$ control diet; $25 \mathrm{HILM}$ and $50 \mathrm{HILM}=$ HILM groups in which soybean meal was replaced with 25 and $50 \%$ of HILM, respectively. 
Table 3. Apparent ileal digestibility of nutrients in broilers fed diets supplemented with Hermetia illucens larvae meal (HILM). ${ }^{1}$

\begin{tabular}{llllll} 
& \multicolumn{2}{c}{ Dietary treatment $^{2}$} & & SEM $^{3}$ & $P$-value \\
\cline { 2 - 4 } & CON & 25HILM & 50HILM & & \\
& & & & & \\
Dry matter (\%) & 61.89 & 55.29 & 49.84 & 5.30 & 0.437 \\
Crude protein (\%) & $70.87^{\mathrm{a}}$ & $60.46^{\mathrm{ab}}$ & $51.38^{\mathrm{b}}$ & 3.85 & 0.040 \\
Energy (\%) & 65.89 & 58.37 & 52.51 & 5.37 & 0.375 \\
\hline
\end{tabular}

${ }^{1}$ Values with different superscripts in the same row are significantly different $(P<0.05)$.

${ }^{2} \mathrm{CON}=$ control diet; $25 \mathrm{HILM}$ and 50HILM = HILM groups in which soybean meal was replaced with 25 and $50 \%$ of HILM, respectively.

${ }^{3}$ SEM, standard error of the mean.

\section{VFA concentration in caecal digesta}

The concentrations of VFAs in the caecal digesta content are presented in Table 5 . The absolute concentrations of all VFAs, except for those of butyrate, increased $(P<0.05)$ in the 50HILM group compared with those in the CON and 25HILM groups. Moreover, short-chain FAs (SCFAs) and branched-chain FAs (BCFAs) were higher $(P<0.05)$ in the $50 \mathrm{HILM}$ group than in the CON and 25HILM groups. The relative concentrations of propionate, isobutyrate, valerate, and isovalerate in the 50HILM group significantly increased $(P<0.05)$, but the concentration of butyrate decreased $(P<0.05)$ with the inclusion of HILM.

\section{Serum parameters and haematological traits}

The results of the serum parameters are shown in Tables 6 and 7. Dietary HILM did not significantly affect serum parameters related to glucose and proteins (Table 6). The serum LDL-C level was lower, whereas the TG level was higher in the 50HILM group $(P<0.05$ and $<0.01$, respectively) than in the $\mathrm{CON}$ group. The serum parameters of liver function, including aspartate aminotransferase, alanine aminotransferase, gamma-glutamyl transferase, alkaline phosphatase, and total bilirubin, were not affected by HILM (Table 7). The serum phosphorus level was lower $(P<0.01)$ in both HILM groups than in the CON group. The CPK activity was the lowest $(P<0.01)$ in the 50HILM group among the other groups.

Haematological traits in broiler chickens are shown in Table 8. Monocyte levels in the blood samples were higher $(P<0.05)$ in the 50HILM group than in the other groups. RDW-CV tended to be higher $(P=0.0790)$ in the 50HILM group and RDW-SD was higher $(P<0.05)$ in the 50HILM group than in the CON group.

\section{Discussion}

As shown in our previous study, the DM and ether extract (EE) of the microwave-dried HILM were 98.53 and 6.16\%, respectively (Kim et al., 2021). According to Schiavone et al. (2017), DM and EE of partially defatted HILM were 94.2 and $18 \%$, on the contrary, highly defatted HILM contains $98.5 \%$ of DM and $4.6 \%$ of EE. Therefore, the HILM that was used in this study can be considered as highly defatted

Table 4. Effects of dietary Hermetia illucens larvae meal (HILM) inclusion level on the relative length and weight of the small intestine in broiler chickens at $35 \mathrm{~d}$ of age. ${ }^{1}$

\begin{tabular}{|c|c|c|c|c|c|}
\hline \multirow[t]{2}{*}{ Item } & \multicolumn{3}{|c|}{ Dietary treatment ${ }^{2}$} & \multirow[t]{2}{*}{ SEM $^{3}$} & \multirow[t]{2}{*}{$P$-value } \\
\hline & CON & 25HILM & 50HILM & & \\
\hline \multicolumn{6}{|c|}{ Relative length (cm/kg LW) } \\
\hline Entire digestive tract & $97.24^{b}$ & $94.79^{b}$ & $110.58^{\mathrm{a}}$ & 3.36 & 0.0093 \\
\hline Duodenum & 14.79 & 15.95 & 18.19 & 0.85 & 0.0510 \\
\hline Jejunum & 42.58 & 38.85 & 44.26 & 1.50 & 0.0593 \\
\hline lleum & $39.86^{b}$ & $39.99^{b}$ & $48.12^{\mathrm{a}}$ & 1.87 & 0.0105 \\
\hline \multicolumn{6}{|c|}{ Relative weight (g/kg LW) } \\
\hline Entire digestive tract & 21.68 & 22.31 & 23.93 & 1.13 & 0.4385 \\
\hline Duodenum & $4.23^{b}$ & $5.41^{a}$ & $4.68^{\mathrm{ab}}$ & 0.29 & 0.0372 \\
\hline Jejunum & 9.87 & 9.33 & 10.15 & 0.61 & 0.6549 \\
\hline lleum & 7.58 & 7.57 & 9.10 & 0.52 & 0.1023 \\
\hline
\end{tabular}


Table 5. Volatile fatty acid (VFA) levels in caecal contents of broiler chickens fed Hermetia illucens larvae meal (HILM). 1,2

\begin{tabular}{|c|c|c|c|c|c|}
\hline \multirow[t]{2}{*}{ Parameter } & \multicolumn{3}{|c|}{ Dietary treatment ${ }^{3}$} & \multirow[t]{2}{*}{ SEM } & \multirow[t]{2}{*}{$P$-value } \\
\hline & CON & 25HILM & 50HILM & & \\
\hline \multicolumn{6}{|c|}{ Absolute value $(\mathrm{mmol} / \mathrm{g})$} \\
\hline Acetate & $75.42^{b}$ & $82.48^{b}$ & $111.25^{\mathrm{a}}$ & 7.18 & 0.0194 \\
\hline Propionate & $6.55^{\mathrm{b}}$ & $5.76^{b}$ & $13.84^{\mathrm{a}}$ & 0.92 & 0.0002 \\
\hline Butyrate & 20.10 & 21.16 & 21.57 & 2.28 & 0.9236 \\
\hline Isobutyrate & $0.55^{b}$ & $0.48^{b}$ & $1.47^{a}$ & 0.12 & 0.0003 \\
\hline Valerate & $1.10^{\mathrm{b}}$ & $1.41^{b}$ & $2.73^{a}$ & 0.26 & 0.0041 \\
\hline Isovalerate & $0.67^{b}$ & $0.45^{\mathrm{b}}$ & $1.66^{\mathrm{a}}$ & 0.20 & 0.0032 \\
\hline $\mathrm{BCFA}^{4}$ & $2.31^{b}$ & $2.26^{b}$ & $5.57^{a}$ & 0.52 & 0.0009 \\
\hline Total SCFA ${ }^{5}$ & $104.39^{b}$ & $111.56^{b}$ & $152.53^{\mathrm{a}}$ & 9.75 & 0.0181 \\
\hline \multicolumn{6}{|c|}{$\begin{array}{l}\text { Relative value ( } \% \text { of } \\
\text { total VFAs) }\end{array}$} \\
\hline Acetate & 72.13 & 73.77 & 73.02 & 0.77 & 0.4310 \\
\hline Propionate & $6.21^{a b}$ & $5.05^{b}$ & $9.17^{a}$ & 0.77 & 0.0108 \\
\hline Butyrate & $19.43^{a}$ & $19.20^{\mathrm{a}}$ & $14.01^{b}$ & 1.38 & 0.0450 \\
\hline Isobutyrate & $0.52^{b}$ & $0.43^{b}$ & $0.96^{a}$ & 0.07 & 0.0013 \\
\hline Valerate & $1.05^{b}$ & $1.21^{\mathrm{ab}}$ & $1.76^{\mathrm{a}}$ & 0.14 & 0.0207 \\
\hline Isovalerate & $0.65^{\mathrm{ab}}$ & $0.40^{b}$ & $1.08^{\mathrm{a}}$ & 0.16 & 0.0306 \\
\hline \multicolumn{6}{|c|}{$\begin{array}{l}{ }^{1} \text { Values with different superscripts in the same row are significantly } \\
\text { different }(P<0.05) \text {. }\end{array}$} \\
\hline \multicolumn{6}{|c|}{$\begin{array}{l}{ }^{2} \text { BCFA = branched-chain fatty acid; SCFA = short-chain fatty acids; SEM = } \\
\text { standard error of the mean. }\end{array}$} \\
\hline \multicolumn{6}{|c|}{$\begin{array}{l}{ }^{3} \mathrm{CON}=\text { control diet; } 25 \mathrm{HILM} \text { and } 50 \mathrm{HILM}=\text { HILM groups in which } \\
\text { soybean meal was replaced with } 25 \text { and } 50 \% \text { of HILM, respectively. } \\
{ }^{4} \text { BCFAs were isobutyrate, valerate, and isovalerate. }\end{array}$} \\
\hline \multicolumn{6}{|c|}{$\begin{array}{l}{ }^{5} \text { Total SCFAs were acetate, propionate, butyrate, isobutyrate, valerate, and } \\
\text { isovalerate. }\end{array}$} \\
\hline
\end{tabular}

larvae meal. It has also been reported that the partially and highly defatted HILM can be a suitable feed ingredient in broiler diets (Schiavone et al., 2017). However, they suggested that the highly defatted HILM has advantages of nutritional composition and storage time due to its higher protein and lower EE content than partially defatted HILM (Schiavone et al., 2017). In this study, the microwave-dried HILM contained 98.53\% DM, 61.24\% CP, and 6.16\% EE. Hence, the microwave-dried HILM can be a suitable feed ingredient in broiler diets; therefore, in this study, we evaluated the microwave-dried HILM as a dietary protein source for broilers.

In the present study, feeding of HILM negatively affected the growth performance of broilers; however, a low inclusion level of HILM may be suitable. Dabbou et al. (2018) also reported that increasing the level of HILM in broiler diets resulted in a linear decrease in growth performance and that the inclusion of $15 \%$ HILM had negative effects on the
Table 6. Effect of dietary Hermetia illucens larvae meal (HILM) inclusion level on the serum glucose, proteins, and lipids of broiler chickens. ${ }^{1,2}$

\begin{tabular}{|c|c|c|c|c|c|}
\hline \multirow[t]{2}{*}{ Parameter } & \multicolumn{3}{|c|}{ Dietary treatment ${ }^{3}$} & \multirow[t]{2}{*}{ SEM } & \multirow[t]{2}{*}{$P$-value } \\
\hline & CON & 25HILM & 50HILM & & \\
\hline Glucose (mg/dl) & 268.40 & 271.38 & 278.50 & 9.23 & 0.7499 \\
\hline \multicolumn{6}{|l|}{ Proteins } \\
\hline Total proteins (g/dl) & 2.75 & 2.60 & 2.64 & 0.12 & 0.7224 \\
\hline Albumin (g/dl) & 1.35 & 1.30 & 1.31 & 0.08 & 0.9187 \\
\hline Globulin (g/dl) & 1.40 & 1.30 & 1.33 & 0.06 & 0.5332 \\
\hline$A / G$ & 1.05 & 1.00 & 1.11 & 0.12 & 0.8539 \\
\hline \multicolumn{6}{|l|}{ Lipids } \\
\hline Cholesterol (mg/dl) & 144.70 & 134.63 & 139.25 & 7.25 & 0.6988 \\
\hline HDL-C (mg/dl) & 115.10 & 107.00 & 105.50 & 4.15 & 0.2813 \\
\hline LDL-C (mg/dl) & $29.00^{a}$ & $12.00^{a b}$ & $10.50^{b}$ & 4.30 & 0.0161 \\
\hline $\mathrm{TG}(\mathrm{mg} / \mathrm{dl})$ & $27.80^{b}$ & $36.13^{a b}$ & $54.33^{a}$ & 5.19 & 0.0058 \\
\hline
\end{tabular}

${ }^{1}$ Values with different superscripts in the same row are significantly different $(P<0.05)$.

${ }^{2} \mathrm{~A} / \mathrm{G}=$ albumin-to-globulin ratio; HDL-C = high-density lipoprotein cholesterol; LDL-C = low-density lipoprotein cholesterol; SEM = standard error of the mean; $\mathrm{TG}=$ triglycerides .

${ }^{3} \mathrm{CON}=$ control diet; $25 \mathrm{HILM}$ and 50HILM = HILM groups in which soybean meal was replaced with 25 and $50 \%$ of HILM, respectively.

FCR and intestinal morphology. They suggested that a low inclusion level of HILM could improve body weight and feed intake during the starter period (Dabbou et al., 2018). We observed that the group with a low substitution level (25\%) of HILM presented a higher average daily gain than the CON group during the first week of the experiment (data not shown). However, the CON group showed better growth performance during the growing and finishing periods. This low growth of HILM-fed broilers may be explained by the low digestibility of nutrients due to the presence of chitin in HILM.

Chitin, a component of the insect exoskeleton, can decrease the digestibility of DM by decreasing the digestibility of protein (Bovera et al., 2018; De Marco et al., 2015). The negative effect of HILM on intestinal morphology may also contribute to the lowering of protein digestibility (Dabbou et al., 2018). Here, the chitin intake by broilers fed HILM during the experimental period was estimated using the following equation (Marono et al., 2015): chitin (\%) = ashfree ADF (\%) - ADF-linked protein (\%). The calculated amount of chitin in the HILM in the present study was $5.70 \%$, and the 25HILM and 50HILM groups ingested approximately 0.28 and $0.50 \mathrm{~g} / \mathrm{d}$ chitin, respectively, considering the feed intake and inclusion levels of HILM in the diets. Bovera et al. (2018) also reported that laying hens 
Table 7. Effect of dietary Hermetia illucens larvae meal (HILM) inclusion level on the electrolytes, liver, renal, and muscle function of the broiler chickens. ${ }^{1,2}$

\begin{tabular}{|c|c|c|c|c|c|}
\hline \multirow[t]{2}{*}{ Parameter } & \multicolumn{3}{|c|}{ Dietary treatment ${ }^{3}$} & \multirow[t]{2}{*}{ SEM } & \multirow[t]{2}{*}{$P$-value } \\
\hline & CON & 25HILM & 50HILM & & \\
\hline \multicolumn{6}{|l|}{ Electrolytes } \\
\hline Phosphorus (U/I) & $6.98^{\mathrm{a}}$ & $3.06^{b}$ & $3.57^{b}$ & 0.79 & 0.0079 \\
\hline Calcium (mg/dl) & 9.17 & 9.09 & 9.10 & 0.93 & 0.9982 \\
\hline \multicolumn{6}{|l|}{ Liver function } \\
\hline AST (U/l) & 189.40 & 182.63 & 182.75 & 9.34 & 0.8675 \\
\hline $\mathrm{ALT}(\mathrm{U} / \mathrm{l})$ & 1.00 & 0.50 & 0.92 & 0.21 & 0.3374 \\
\hline GGT (U/l) & 15.60 & 12.50 & 12.00 & 1.69 & 0.3323 \\
\hline ALP (U/I) & $1,298.50$ & $1,323.63$ & $1,500.17$ & 103.22 & 0.3697 \\
\hline Total bilirubin (mg/dl) & 0.03 & 0.04 & 0.03 & 0.01 & 0.5272 \\
\hline \multicolumn{6}{|c|}{ Renal and muscle function } \\
\hline $\mathrm{BUN}(\mathrm{mg} / \mathrm{dl})$ & 0.72 & 0.51 & 0.71 & 0.09 & 0.3464 \\
\hline Creatinine (mg/dl) & 0.27 & 0.18 & 0.25 & 0.05 & 0.5567 \\
\hline CPK (U/I) & $4,575.70^{\mathrm{a}}$ & $3,005.39^{a b}$ & $1,800.81^{b}$ & 541.92 & 0.0072 \\
\hline
\end{tabular}

Table 8. Effects of dietary Hermetia illucens larvae meal (HILM) inclusion level on the haematological traits of broiler chickens. ${ }^{1,2}$

\begin{tabular}{|c|c|c|c|c|c|}
\hline \multirow[t]{2}{*}{ Parameter } & \multicolumn{3}{|c|}{ Dietary treatment ${ }^{3}$} & \multirow[t]{2}{*}{ SEM } & \multirow[t]{2}{*}{$P$-value } \\
\hline & CON & 25HILM & 50HILM & & \\
\hline WBC $\left(\times 10^{9} / 1\right)$ & 21.53 & 17.87 & 18.34 & 1.56 & 0.2556 \\
\hline Heterophils (\%) & 32.88 & 25.65 & 29.98 & 2.63 & 0.2625 \\
\hline Lymphocytes (\%) & 49.07 & 58.02 & 48.48 & 3.75 & 0.2643 \\
\hline Monocytes (\%) & $12.66^{b}$ & $11.67^{b}$ & $16.41^{a}$ & 1.03 & 0.0148 \\
\hline Eosinophils (\%) & 5.27 & 4.48 & 4.97 & 0.64 & 0.7553 \\
\hline Basophils (\%) & 0.12 & 0.18 & 0.16 & 0.06 & 0.8113 \\
\hline $\mathrm{H} / \mathrm{L}$ & 0.79 & 0.46 & 0.66 & 0.11 & 0.1858 \\
\hline $\operatorname{RBC}\left(\times 10^{12} / \mathrm{l}\right)$ & 2.43 & 2.19 & 2.11 & 0.11 & 0.1048 \\
\hline Haemoglobin (g/l) & 12.17 & 11.12 & 10.71 & 0.56 & 0.1902 \\
\hline Haematocrit (\%) & 32.50 & 29.73 & 29.36 & 1.53 & 0.3210 \\
\hline RDW-CV & 8.69 & 8.63 & 9.09 & 0.14 & 0.0790 \\
\hline RDW-SD & $48.58^{b}$ & $49.23^{a b}$ & $52.50^{a}$ & 1.03 & 0.0317 \\
\hline
\end{tabular}

${ }^{1}$ Values with different superscripts in the same row are significantly different $(P<0.05)$.

${ }^{2} \mathrm{H} / \mathrm{L}=$ heterophils to lymphocytes ratio; RBC = red blood cells; RDW-CV $=$ red blood cell distribution width-coefficient of variation; RDW-SD $=$ red blood cell distribution width-standard deviation; SEM = standard error of the mean; $\mathrm{WBC}=$ white blood cells.

${ }^{3} \mathrm{CON}=$ control diet; $25 \mathrm{HILM}$ and 50HILM = HILM groups in which soybean meal was replaced with 25 and $50 \%$ of HILM, respectively.
(16 weeks old) that ingested approximately $0.47 \mathrm{~g} / \mathrm{d}$ chitin showed lower protein digestibility than those fed SBMbased diets. Furthermore, we focused on structural changes in the manufacturing process of HILM. Although previous studies did not report the method of HILM manufacture, the HILM used in this study was microwave-dried. The microwave drying method makes HILM more compact via polymerisation of the protein particles but decreases protein digestibility compared with HILM manufactured using conventional drying methods (Huang et al., 2019). Thus, the AID of the protein was substantially decreased by the substitution of HILM. Furthermore, the reduced AID of DM and energy ( -19.47 and $-20.31 \%$, respectively) in the 50HILM group compared with that in the CON group was can be ascribed to strongly reduced protein digestibility (-27.50\%).

Decreased nutrient digestibility is also related to the length and weight of the digestive intestinal tract. As the ileum length increased, the relative length of the entire small intestinal tract increased in the 50HILM group. An increase in the ileum length of broilers and laying hens fed insect meals has been reported previously (Bovera et al., 2016, 2018). These results are typically ascribed to the effects of undigestible substances (Borin et al., 2006). However, in this study, the compensative effect for increasing nutrient absorption via elongation of the ileum in HILM-fed broilers appeared to be greater than the peristaltic activity caused by chitin (Borin et al., 2006; Bovera et al., 2018). Moreover, 
the elongation effect of the intestinal tract by HILM seems to be greater in the early growth stage than in other stages (Bovera et al., 2018).

HILM-fed broilers showed higher production of VFAs in the caecal content caused by chitin. Chitin has been suggested as a potential prebiotic substance because it is undegradable and unabsorbable (Bovera et al., 2015). In the present study, 50HILM treatment increased the absolute value of total VFAs, except that of butyrate. However, 25HILM treatment did not increase the total SCFA production, which agrees with the findings of Moniello et al. (2019). Thus, chitin intake was not sufficient to have a prebiotic effect. Unlike previous study results, the propionate level was also increased in the 50HILM group (Cutrignelli et al., 2018; Moniello et al., 2019). Kim et al. (2020) reported that black soldier fly larvae oil mostly affected propionate level. This result was ascribed to the inhibitory activities of medium-chain FAs (MCFAs), which are present in high quantities in black soldier fly larvae oil. Here, the analysis of the FA profile of HILM revealed a high percentage of MCFAs. Therefore, the difference in the FA profiles of the ingredients (HILM vs SBM) may have affected the propionate level.

Increased VFA levels are also related to feed intake via the control of satiety and hunger, as it has been reported that elevated propionate levels reduce eating behaviour by affecting satiety through brain striatal pathways (Bedford et al., 2020; Byrne et al., 2016). Therefore, in the present study, the decreased feed intake may have been affected by the elevated caecal propionate level; infusion of propionate altered the feeding behaviour and decreased energy intake, supporting this prediction (Oba and Allen, 2003).

Although an increase in the total SCFA levels in HILMfed broilers indicates an improvement in the gut health, a concern is that the relative value of BCFAs (isobutyrate, valerate, and isovalerate) also increased. This increase can be promoted by protein fermentation in the gut, generating protein fermentation products (e.g. ammonia, amines, and phenol) (Diether and Willing, 2019; Gilbert et al., 2018; Rios-Covian et al., 2020). Undigested protein and amino acids caused by poor ileal digestibility may also promote fermentation in the cecum, which could decrease the relative value of butyrate (Russell et al., 2011). Increased propionate and decreased butyrate levels could also be ascribed to the flux of butyrate to propionate by decreased feed intake (Bedford et al., 2020).

The effects of chitin and different FA profiles of HILM and SBM on blood traits were investigated by examining the serum protein and lipid levels. It has been shown that the prebiotic effect of chitin lowers A/G, which indicates a better immune response and disease resistance (Bovera et al., 2015; Marono et al., 2017). However, in the present study, the A/G was not altered, because of the lower chitin intake by broilers, in contrast to the results of a previous study (Marono et al., 2017). Commercial chitin has also been reported to decrease lipid absorption by binding to lipids; therefore, it lowers plasma cholesterol (El-Gobary et al., 2016). Moreover, the effects of HILM in terms of lowering serum cholesterol and TG levels in laying hens have been attributed to chitin (Bovera et al., 2018; Marono et al., 2017). However, here, we observed that the TG level was increased by HILM. Although the reason for this is not clear, the high level of MCFAs in HILM may have affected serum lipids such as LDL-C and TG, because of lower chitin ingestion by broilers in our study than by laying hens in their studies. MCFAs have a smaller molecular size and hence have a lower weight than long-chain FAs, facilitating rapid absorption into the portal vein (Baltić et al., 2017; Hanczakowska, 2017). This characteristic may lead to a decrease in the level of LDL-C, and several previous studies have shown that MCFA decreased LDL-C and increased TG (Baltić et al., 2019; Hill et al., 1990; Sung et al., 2018). Here, the relative weight of the duodenum in the 25HILM group was increased, possibly because of its higher relative length compared with that in the CON group. However, the cause of this increased relative weight may be the proliferation of the intestinal mucosa because of the fast-absorbing property of MCFAs in HILM (Zeitz et al., 2015).

Clinical signs in chickens were not observed during the experiment; they were verified by the serum parameters that indicated liver, renal, and muscle functions. However, phosphorus was decreased in HILM-fed broilers, in contrast to previous study result, that is, phosphorous showed high bioavailability and was obtained from insects (Dabbou et al., 2018). It has been reported that chitosan, which is a deacetylated form of chitin, reduced serum phosphorus in rats (Baxter et al., 2000). According to Pap et al. (2020), chitosan can bind to phosphorus via its amine group ($\mathrm{NH}_{2}$ ), and the similar structure of chitin with chitosan may explain the observed decrease in serum phosphorus. The CPK level decreased in the 50HILM group, which may be ascribed to the low muscle mass caused by the lower final body weight of HILM-fed broilers (Garcia and Creatine, 1974; Yen et al., 2017).

Information regarding the effect of HILM on RDW in broilers is limited. We observed that RDW-CV and RDWSD were slightly and significantly increased, respectively, with the inclusion level of HILM. The increased RDW level has been reported to be related to the size of red blood cells, which may be linked to problems such as dysfunction, malnutrition, and chronic liver disease (Reddy et al., 2018). The reason for the significantly higher levels of monocytes in the blood of HILM-fed broilers is not completely clear. Additionally, there was no difference in monocyte levels in HILM-fed laying hens compared with those in SBM-fed laying hens in a previous study (Marono 
et al., 2017). However, it has been reported that protein energy malnutrition increases blood monocyte levels in mice (Corware et al., 2014). Therefore, malnutrition caused by low nutrient digestibility in the 50HILM group may have increased the monocyte and RDW-SD levels.

\section{Conclusions}

We determined the effects of microwave-dried HILM, in terms of chitin content and FA profiles, on the growth performance and health of broilers. HILM substitution in broiler diets showed positive effects on the SCFA concentrations. Additionally, HILM affected serum lipid parameters; a higher MCFA content was observed in broilers fed HILM than those fed SBM. However, poor results in terms of growth performance and digestibility in HILM-fed broilers suggest that the protein source in HILM was polymerised during drying and that undigested protein affected the BCFA concentrations in the caecal digesta. Furthermore, the analysis of the haematological traits suggested that HILM-fed broilers suffered from malnutrition due to the low digestibility of nutrients. Therefore, further studies to overcome the limitations of microwave-dried HILM and improve protein digestibility by improving the manufacturing process (e.g. control of energy output and drying time) are needed.

\section{Acknowledgements}

This research was supported by the 'Cooperative Research Program for Agriculture Science and Technology Development (Project No. PJ01456002)' and the 2021 RDA Fellowship Program of the National Institute of Animal Science, Rural Development Administration, Republic of Korea. We gratefully acknowledge all team members who helped either directly or indirectly when conducting this study.

\section{Conflict of interest}

The authors declare no conflict of interest.

\section{References}

Association Official Analytical Chemists (AOAC), 2005. Official methods of analysis, $18^{\text {th }}$ edition. AOAC, Arlington, VA, USA.

Baltić, B., Ćirić, J., Šefer, D., Radovanović, A., Đorđević, J., Glišić, M., Bošković, M., Baltić, M.Ž., Đorđević, V. and Marković, R., 2019. Effect of dietary supplementation with medium chain fatty acids on growth performance, intestinal histomorphology, lipid profile and intestinal microflora of broiler chickens. South African Journal of Animal Science 48: 885. https://doi.org/10.4314/sajas.v48i5.8

Baltić, B., Starčević, M., Đorđević, J., Mrdović, B. and Marković, R., 2017. Importance of medium chain fatty acids in animal nutrition. IOP Conference Series: Earth and Environmental Science 85: 12048. https://doi.org/10.1088/1755-1315/85/1/012048
Baxter, J., Shimizu, F., Takiguchi, Y., Wada, M. and Yamaguchi, T., 2000. Effect of iron (III) chitosan intake on the reduction of serum phosphorus in rats. Journal of Pharmacy and Pharmacology 52: 863-874. https://doi.org/10.1211/0022357001774552

Bedford, A., Beckett, L., Harthan, L., Wang, C., Jiang, N., Schramm, H., Guan, L.L., Daniels, K.M., Hanigan, M.D. and White, R.R., 2020. Ruminal volatile fatty acid absorption is affected by elevated ambient temperature. Scientific Reports 10, Article number: 13092. https://doi.org/10.1038/s41598-020-69915-x

Borin, K., Lindberg, J.E. and Ogle, R.B., 2006. Digestibility and digestive organ development in indigenous and improved chickens and ducks fed diets with increasing inclusion levels of cassava leaf meal. Journal of Animal Physiology and Animal Nutrition 90: 230-237. https:// doi.org/10.1111/j.1439-0396.2005.00586.x

Borrelli, L., Coretti, L., Dipineto, L., Bovera, F., Menna, F., Chiariotti, L., Nizza, A., Lembo, F. and Fioretti, A., 2017. Insect-based diet, a promising nutritional source, modulates gut microbiota composition and SCFAs production in laying hens. Scientific Reports 7, Article number: 16269. https://doi.org/10.1038/s41598-017-16560-6

Bovera, F., Loponte, R., Marono, S., Piccolo, G., Parisi, G., Iaconisi, V., Gasco, L. and Nizza, A., 2016. Use of Tenebrio molitor larvae meal as protein source in broiler diet: effect on growth performance, nutrient digestibility, and carcass and meat traits. Journal of Animal Science 94: 639-647. https://doi.org/10.2527/jas.2015-9201

Bovera, F., Loponte, R., Pero, M.E., Cutrignelli, M.I., Calabrò, S., Musco, N., Vassalotti, G., Panettieri, V., Lombardi, P., Piccolo, G., Di Meo, C., Siddi, G., Fliegerova, K. and Moniello, G., 2018. Laying performance, blood profiles, nutrient digestibility and inner organs traits of hens fed an insect meal from Hermetia illucens larvae. Research in Veterinary Science 120: 86-93. https://doi.org/10.1016/j. rvsc.2018.09.006

Bovera, F., Piccolo, G., Gasco, L., Marono, S., Loponte, R., Vassalotti, G., Mastellone, V., Lombardi, P., Attia, Y.A. and Nizza, A., 2015. Yellow mealworm larvae (Tenebrio molitor, L.) as a possible alternative to soybean meal in broiler diets. British Poultry Science 56: 569-575. https://doi.org/10.1080/00071668.2015.1080815

Byrne, C., Chambers, E., Alhabeeb, H., Preston, T., Chhina, N., Busza, A., Fitzpatrick, J., Irani, C., Morrison, D., Goldstone, A. and Frost, G., 2016. Increased colonic propionate reduces anticipatory food reward responses in the human striatum. American Journal of Clinical Nutrition 104: 5-14. https://doi.org/10.3945\%2Fajcn.115.126706

Corware, K., Yardley, V., Mack, C., Schuster, S., Al-Hassi, H., Herath, S., Bergin, P., Modolell, M., Munder, M., Müller, I. and Kropf, P., 2014. Protein energy malnutrition increases arginase activity in monocytes and macrophages. Nutrition Metabolism 11, Article number: 51. https://doi.org/10.1186/1743-7075-11-51

Cutrignelli, M.I., Messina, M., Tulli, F., Randazzi, B., Olivotto, I., Gasco, L., Loponte, R. and Bovera, F., 2018. Evaluation of an insect meal of the black soldier fly (Hermetia illucens) as soybean substitute: intestinal morphometry, enzymatic and microbial activity in laying hens. Research in Veterinary Science 117: 209-215. https://doi. org/10.1016/j.rvsc.2017.12.020 
Dabbou, S., Gai, F., Biasato, I., Capucchio, M.T., Biasibetti, E., Dezzutto, D., Meneguz, M., Plachà, I., Gasco, L. and Schiavone, A., 2018. Black soldier fly defatted meal as a dietary protein source for broiler chickens: effects on growth performance, blood traits, gut morphology and histological features. Journal of Animal Science and Biotechnology 9, Article number: 49. https://doi.org/10.1186/ s40104-018-0266-9

De Marco, M., Martínez, S., Hernandez, F., Madrid, J., Gai, F., Rotolo, L., Belforti, M., Bergero, D., Katz, H., Dabbou, S., Kovitvadhi, A., Zoccarato, I., Gasco, L. and Schiavone, A., 2015. Nutritional value of two insect larval meals (Tenebrio molitor and Hermetia illucens) for broiler chickens: apparent nutrient digestibility, apparent ileal amino acid digestibility and apparent metabolizable energy. Animal Feed Science and Technology 209: 211-218. https://doi.org/10.1016/j. anifeedsci.2015.08.006

Diener, S., Zurbrügg, C. and Tockner, K., 2015. Bioaccumulation of heavy metals in the black soldier fly, Hermetia illucens and effects on its life cycle. Journal of Insects as Food and Feed 1: 261-270. https://doi.org/10.3920/JIFF2015.0030.

Diether, N.E. and Willing, B.P., 2019. Microbial fermentation of dietary protein: an important factor in diet-microbe-host interaction. Microorganisms 7: 19. https://doi.org/10.3390/ microorganisms7010019

El-Gobary, G.I.A., El-Zoghby, A.F.M., El-Sheikh, N.I. and Hamdy, A.S., 2016. Effect of chito-oligosaccharide as feed additives on egg production and performance of laying hens. Egyptian Journal of Chemistry and Environmental Health 2: 183-194.

Garcia, W. and Creatine, E., 1974. Elevated creatine phosphokinase levels associated with large muscle mass: another pitfall in evaluating clinical significance of total serum CPK activity. The Journal of the American Medical Association 228: 1395-1396. https://doi. org/10.1001/jama.1974.03230360025017

Gasco, L., Acuti, G., Bani, P., Dalle Zotte, A., Danieli, P.P., De Angelis, A., Fortina, R., Marino, R., Parisi, G., Piccolo, G., Pinotti, L., Prandini, A., Schivone, A., Terova, G., Tulli, F. and Roncarati, A., 2020. Insect and fish by-products as sustainable alternatives to conventional animal proteins in animal nutrition. Italian Journal of Animal Science 19: 360-372. https://doi.org/10.1080/182805 1X.2020.1743209

Gilbert, M.S., Ijssennagger, N., Kies, A.K. and Van Mil, S.W.C., 2018. Protein fermentation in the gut; implications for intestinal dysfunction in humans, pigs, and poultry. American Journal of Physiology-Gastrointestinal and Liver Physiology 315: G159-G170. https://doi.org/10.1152/ajpgi.00319.2017

Hanczakowska, E., 2017. The use of medium-chain fatty acids in piglet feeding - a review. Annals of Animal Science 17: 967-977. https:// doi.org/10.1515/aoas-2016-0099

Hill, J.O., Peters, J.C., Swift, L.I., Yang, D., Sharp, T., Abumrad, N. and Greene, H.L., 1990. Changes in blood lipids during six days of overfeeding with medium or long chain triglycerides. Journal of Lipid Research 31: 407-416.
Huang, C., Feng, W., Xiong, J., Wang, T., Wang, W., Wang, C. and Yang, F., 2019. Impact of drying method on the nutritional value of the edible insect protein from black soldier fly (Hermetia illucens L.) larvae: amino acid composition, nutritional value evaluation, in vitro digestibility, and thermal properties. European Food Research and Technology 245: 11-21. https://doi.org/10.1007/s00217-018-3136-y Kawasaki, K., Hashimoto, Y., Hori, A., Kawasaki, T., Hirayasu, H., Iwase, S.I., Hashizume, A., Ido, A., Miura, C., Miura, T., Nakamura, S., Seyama, T., Matsumoto, Y., Kasai, K. and Fujitani, Y., 2019. Evaluation of black soldier fly (Hermetia illucens) larvae and prepupae raised on household organic waste, as potential ingredients for poultry feed. Animals 9: 98. https://doi.org/10.3390/ani9030098

National Institute of Animal Science (NIAS), 2017. Korean feeding standard for poultry, $3^{\text {rd }}$ edition. Nutrient requirements of poultry. National Institute of Animal Science, Wanju-gun, Korea.

Khodifad, B.C. and Dhamsaniya, N.K., 2020. Drying of food materials by microwave energy - a review. International Journal of Current Microbiology and Applied Science 9: 1950-1973. https://doi. org/10.20546/ijcmas.2020.905.223

Kim, Y.B., Kim, D.H., Jeong, S.B., Lee, J.W., Kim, T.H., Lee, H.G. and Lee, K.W., 2020. Black soldier fly larvae oil as an alternative fat source in broiler nutrition. Poultry Science 99: 3133-3143. https:// doi.org/10.1016/j.psj.2020.01.018

Kim, B., Kim, H.R., Lee, S., Baek, Y.-C, Jeong, J.Y., Bang, H.T., Ji, S. Y. and Park, S.H., 2021. Effects of dietary inclusion level of microwavedried and press-defatted black soldier fly (Hermetia illucens) larvae meal on carcass traits and meat quality in broilers. Animals 11: 665. https://doi.org/10.3390/ani11030665

Lenaerts, S., Van der Borght, M., Callens, A., Van Campenhout, L., 2018. Suitability of microwave drying for mealworms (Tenebrio molitor) as alternative to freeze drying: impact on nutritional quality and colour. Food Chemistry 254: 129-136. https://doi.org/10.1016/j. foodchem.2018.02.006

Longvah, T., Mangthya, K. and Ramulu, P., 2011. Nutrient composition and protein quality evaluation of eri silkworm (Samia ricinii) prepupae and pupae. Food Chemistry 128: 400-403. https://doi. org/10.1016/j.foodchem.2011.03.041

Marono, S., Loponte, R., Lombardi, P., Vassalotti, G., Pero, M.E., Russo, F., Gasco, L., Parisi, G., Piccolo, G., Nizza, S., Di Meo, C., Attia, Y.A. and Bovera, F., 2017. Productive performance and blood profiles of laying hens fed Hermetia illucens larvae meal as total replacement of soybean meal from 24 to 45 weeks of age. Poultry Science 96: 1783-1790. https://doi.org/10.3382/ps/pew461

Marono, S., Piccolo, G., Loponte, R., Di Meo, C., Attia, Y.A., Nizza, A. and Bovera, F., 2015. In vitro crude protein digestibility of Tenebrio molitor and Hermetia illucens insect meals and its correlation with chemical composition traits. Italian Journal of Animal Science 14: 338-343. https://doi.org/10.4081/ijas.2015.3889

Moniello, G., Ariano, A., Panettieri, V., Tulli, F., Olivotto, I., Messina, M., Randazzo, B., Severino, L., Piccolo, G., Musco, N., Addeo, N.F., Hassoun, G. and Bovera, F., 2019. Intestinal morphometry, enzymatic and microbial activity in laying hens fed different levels of a Hermetia illucens larvae meal and toxic elements content of the insect meal and diets. Animals 9: 86. https://doi.org/10.3390/ ani9030086 
Nafisah, A., Nahrowi, Mutia, R. and Jayanegara, A., 2019. Chemical composition, chitin and cell wall nitrogen content of black soldier fly (Hermetia illucens) larvae after physical and biological treatment. IOP Conference Series: Materials Science and Engineering 546: 7-12. https://doi.org/10.1088/1757-899X/546/4/042028

Oba, M. and Allen, M.S., 2003. Intraruminal infusion of propionate alters feeding behavior and decreases energy intake of lactating dairy cows. Journal of Nutrition 133: 1094-1099. https://doi.org/10.1093/ jn/133.4.1094

Pap, S., Kirk, C., Bremner, B., Turk Sekulic, M., Gibb, S.W., Maletic, S. and Taggart, M.A., 2020. Synthesis optimisation and characterisation of chitosan-calcite adsorbent from fishery-food waste for phosphorus removal. Environmental Science and Pollution Research 27: 9790-9802. https://doi.org/10.1007/s11356-019-07570-0

Park, S.-H., Kim, H.-R., Baek, Y.-C., Ryu, C.-H., Ji, S.-Y., Jeong, J.-Y., Kim, M., Jung, H. and Kim, B., 2021. Effects of dietary inclusion level of microwave-dried and press-defatted black soldier fly (Hermetia illucens) larvae meal on productive performance, cecal volatile fatty acid profile, and egg quality in laying hens. Animals 11: 1486. https://doi.org/10.3390/ani11061486

Reddy, K.E., Song, J., Lee, J.H., Kim, M., Kim, Dong Wook, Jung, H.J., Kim, B., Lee, Y., Yu, D., Kim, Dong Woon, Oh, Y.K. and Lee, S.D., 2018. Effects of high levels of deoxynivalenol and zearalenone on growth performance, and hematological and immunological parameters in pigs. Toxins 10: 114. https://doi.org/10.3390/ toxins10030114

Rios-Covian, D., González, S., Nogacka, A.M., Arboleya, S., Salazar, N., Gueimonde, M. and De los Reyes-Gavilán, C.G., 2020. An overview on fecal branched short-chain fatty acids along human life and as related with body mass index: associated dietary and anthropometric factors. Frontiers in Microbiology 11: 973. https://doi.org/10.3389/ fmicb.2020.00973

Russell, W.R., Gratz, S.W., Duncan, S.H., Holtrop, G., Ince, J., Scobbie, L., Duncan, G., Johnstone, A.M., Lobley, G.E., Wallace, R.J., Duthie, G.G. and Flint, J.H., 2011. High-protein, reduced-carbohydrate weight-loss diets promote metabolite profiles likely to be detrimental to colonic health. American Journal of Clinical Nutrition 93: 10621072. https://doi.org/10.3945/ajcn.110.002188

SAS, 2009. SAS User's Guide. version 9.4. SAS Institute Inc., Cary, NC, USA.

Schiavone, A., Dabbou, S., Petracci, M., Zampiga, M., Sirri, F., Biasato, I., Gai, F. and Gasco, L., 2019. Black soldier fly defatted meal as a dietary protein source for broiler chickens: effects on carcass traits, breast meat quality and safety. Animal 13: 2397-2405. https://doi. org/10.1017/S1751731119000685
Schiavone, A., De Marco, M., Martínez, S., Dabbou, S., Renna, M., Madrid, J., Hernandez, F., Rotolo, L., Costa, P., Gai, F. and Gasco, L., 2017. Nutritional value of a partially defatted and a highly defatted black soldier fly larvae (Hermetia illucens L.) meal for broiler chickens: apparent nutrient digestibility, apparent metabolizable energy and apparent ileal amino acid digestibility. Journal of Animal Science and Biotechnology 8, Article number: 51. https://doi. org/10.1186/s40104-017-0181-5

Stein, H.H., Sève, B., Fuller, M.F., Moughan, P.J. and De Lange, C.F.M., 2007. Invited review: amino acid bioavailability and digestibility in pig feed ingredients: terminology and application. Journal of Animal Science 85: 172-180. https://doi.org/10.2527/jas.2005-742

Sung, M.H., Liao, F.H. and Chien, Y.W., 2018. Medium-chain triglycerides lower blood lipids and body weight in streptozotocininduced type 2 diabetes rats. Nutrients 10: 963. https://doi. org/10.3390/nu10080963

Surendra, K.C., Olivier, R., Tomberlin, J.K., Jha, R. and Khanal, S.K., 2016. Bioconversion of organic wastes into biodiesel and animal feed via insect farming. Renewable Energy 98: 197-202. https://doi. org/10.1016/j.renene.2016.03.022

Suzuki, M., Fujimoto, W., Goto, M., Morimatsu, M., Syuto, B. and Iwanaga, T., 2002. Cellular expression of gut chitinase mRNA in the gastrointestinal tract of mice and chickens. Journal of Histochemistry \& Cytochemistry 50: 1081-1089. https://doi. org/10.1177/002215540205000810

Tabata, E., Kashimura, A., Wakita, S., Ohno, M., Sakaguchi, M., Sugahara, Y., Kino, Y., Matoska, V., Bauer, P.O. and Oyama, F., 2017. Gastric and intestinal proteases resistance of chicken acidic chitinase nominates chitin-containing organisms for alternative whole edible diets for poultry. Scientific Reports 7, Article number: 6662. https://doi.org/10.1038/s41598-017-07146-3

Veldkamp, T., Van Duinkerken, G., Van Huis, A., Lakemond, C.M.M., Ottevanger, E., Bosch, G. and Van Boekel, M.A.J.S., 2012. Insects as a sustainable feed ingredient in pig and poultry diets - a feasibility study. Report 638, Wageningen UR Livestock Research, Wageningen, the Netherlands.

Yen, C.H., Te Wang, K., Lee, P.Y., Liu, C.C., Hsieh, Y.C., Kuo, J.Y., Bulwer, B.E., Hung, C.L., Chang, S.C., Shih, S.C., Hu, K.C., Yeh, H.I. and Lam, C.S.P., 2017. Gender-differences in the associations between circulating creatine kinase, blood pressure, body mass and non-alcoholic fatty liver disease in asymptomatic asians. PLoS ONE 12: e0179898. https://doi.org/10.1371/journal.pone.0179898

Zeitz, J.O., Fennhoff, J., Kluge, H., Stangl, G.I. and Eder, K., 2015. Effects of dietary fats rich in lauric and myristic acid on performance, intestinal morphology, gut microbes, and meat quality in broilers. Poultry Science 94: 2404-2413. https://doi.org/10.3382/ps/pev191 
